Carbohydrate and amino acid metabolism in rat cerebral cortex in moderate and extreme hypercapnia.

Quistorff, Bjørn; Folbergrová, J.; Norberg, Karin; K. Siesjö, Bo

Published in:

Journal of Neurochemistry

Publication date:

1975

Document version

Publisher's PDF, also known as Version of record

Citation for published version (APA):

Quistorff, B., Folbergrová, J., Norberg, K., \& K. Siesjö, B. (1975). Carbohydrate and amino acid metabolism in rat cerebral cortex in moderate and extreme hypercapnia. Journal of Neurochemistry, 25(4), 457-462. 


\title{
CARBOHYDRATE AND AMINO ACID METABOLISM IN RAT CEREBRAL CORTEX IN MODERATE AND EXTREME HYPERCAPNIA
}

\author{
J. Folbergrová, ${ }^{1}$ K. Norberg, B. QuistorfF and B. K. SiesJö \\ Brain Research Laboratory, E-Blocket, University Hospital, Lund, Sweden, \\ and \\ Department of Biochemistry A, University of Copenhagen, Denmark
}

(Received 28 February 1975. Accepted 13 March 1975)

\begin{abstract}
The time course of changes in glycolytic and citric acid cycle intermediates and in amino acids was studied in acute and steady state hypercapnia. Experiments on unanaesthetized animals exposed to $10 \% \mathrm{CO}_{2}$ for 10,20 and $60 \mathrm{~s}$ showed that there was a transient decrease in glycogen concentration, progressive increases in glucose-6-phosphate and fructose-6-phosphate and decreases in pyruvate and lactate. During this time the levels of amino acids and Krebs cycle intermediates did not change, except for a small fall in malate at $60 \mathrm{~s}$. The results indicate that there was a decrease in glycolytic flux due to an inhibition of the phosphofructokinase reaction. Since the tissue levels of phosphocreatine, ATP, ADP and AMP were unchanged inhibition of phosphofructokinase was probably due to the fall in $\mathrm{pH}$.

Anaesthetized animals were exposed to about $5 \% \mathrm{CO}_{2}$ (for 2, 5, 15, 30 and $60 \mathrm{~min}$ ) or to about $45 \% \mathrm{CO}_{2}$ (for 5 and $15 \mathrm{~min}$ ). Except for succinate, which increased, all citric acid cycle metabolites analysed (citrate, $\alpha$-ketoglutarate, fumarate and malate) decreased with the rise in $\mathrm{CO}_{2}$-tension. The sum of the amino acids analysed (glutamate, glutamine, aspartate, asparagine, alanine and GABA) decreased at extreme hypercapnia. The results suggest that Krebs cycle intermediates and amino acids are partly used as substrates for energy production when there is reduced pyruvate availability due to hypercapnia.

It is proposed that amino acid carbon is made available for oxidation via transamination (aspartate aminotransferase reaction) and deamination (glutamate dehydrogenase reaction) and that citric acid cycle intermediates are metabolized following a reversal of reactions usually leading to $\mathrm{CO}_{2}$ fixation.
\end{abstract}

PREvious results from this laboratory have shown that hypercapnia reduces the tissue concentrations of pyruvate and lactate as well as of the Krebs cycle intermediates citrate, $\alpha$-ketoglutarate $(\alpha-\mathrm{KG})$ and malate (FOLBERGROVÁ et al., 1972b, 1974a). Although information on changes in succinate and fumarate was not at hand, it was speculated that the increased $\mathrm{CO}_{2}$ tensions led to a loss of carbon skeletons from the Krebs cycle. The cause of this hypothetical loss was not apparent in view of the fact that hypercapnic conditions may favour anaplerotic reactions due to $\mathrm{CO}_{2}$ fixation. Since there was a decrease in the sum of the concentrations of glutamate, glutamine and aspartate (FolBERGROví et al., 1974a), a shift of carbon atoms from the Krebs cycle to the amino acid pool did not seem likely. However, firm conclusions could not be drawn since the tissue concentrations of alanine and GABA were not measured.

The present experiments were undertaken to obtain additional information on changes affecting carbo-

\footnotetext{
${ }^{1}$ On leave of absence from Institute of Physiology, Czechoslovak Academy of Sciences, Prague.

Abbreviations used: $\alpha-\mathrm{KG}, \alpha$-ketoglutarate; FDH, fructose-1,6-diphosphate; DHAP, dihydroxyacetone phosphate; 3PG, 3-phosphoglycerate; $\mathrm{PCr}$, phosphocreatine; PFK, phosphofructokinase; OAA, oxaloacetate.
}

hydrate and amino acid metabolism in the cerebral cortex in hypercapnia, and to allow defining the mechanisms involved. The following three aspects were studied. Firstly, in order to characterize the initial events, unanaesthetized animals were exposed to about $10 \% \mathrm{CO}_{2}$ and cerebral cortex was obtained for analyses after 10,20 or $60 \mathrm{~s}$ of hypercapnia. Secondly, a more complete picture of citric acid cycle changes was obtained by measuring, apart from citrate, $\alpha$-ketoglutarate and malate, also isocitrate, succinate and fumarate. Since the major part of the citric acid cycle intermediates was measured changes in the size of this pool could be estimated. Thirdly, the previous estimation of amino acid changes, as based on measurements of glutamate, glutamine and aspartate, was extended to include measurements of GABA, asparagine and alanine. Therefore, citric acid cycle intermediates and amino acids were measured in animals exposed to about $5 \% \mathrm{CO}_{2}$ (for $2,5,15$, 30 and $60 \mathrm{~min}$ ) or to about $45 \% \mathrm{CO}_{2}$ (for 5 and $15 \mathrm{~min})$. The results obtained allow a tentative interpretation of the mechanisms whereby hypercapnia influences substrate utilization in the brain.

\section{METHODS}

The experiments were performed on male Wistar rats that were allowed free access to pellet food and water until 
operation. There were two main groups: unanaesthetized and anaesthetized. The unanaesthetized animals (205$225 \mathrm{~g}$ ) were provided with indwelling tail artery catheters in a previous operation performed under halothane anaesthesia. When they had recovered completely from this operation they were introduced into the plastic cylinder of the 'freeze-clamping' apparatus (QUisTORFF, 1975; NoRBERG et al., 1975). The cylinder was initially flushed with room air at a rate of $51 / \mathrm{min}$. After allowing a steady period of 15-20 min an arterial blood sample was taken for control of blood gases and pH. The 'flushing gas-mixture' was then changed to $20 \% \mathrm{CO}_{2}$ and $20 \% \mathrm{O}_{2}$ in nitrogen, and after about $10 \mathrm{~s}$ of hypercapnia changed to $10 \% \mathrm{CO}_{2}$ and $20 \% \mathrm{O}_{2}$ in nitrogen. Brain tissue was sampled for analysis by means of 'freeze-clamping' following 10,20 and $60 \mathrm{~s}$ of hypercapnia. An arterial blood sample was drawn from all animals for determination of $\mathrm{P}_{\mathrm{O}_{2}}$ and $\mathrm{P}_{\mathrm{CO}_{2}}$ at the moment of sampling.

In the anaesthetized series anaesthesia was induced with $2-3 \%$ halothane to allow tracheotomy and immobilization with tubocurarine chloride. The animals were maintained on $70 \% \mathrm{~N}_{2} \mathrm{O}$ and $30 \% \mathrm{O}_{2}$ and ventilated to an arterial $\mathrm{P}_{\mathrm{CO}_{2}}$ of $35-40 \mathrm{~mm} \mathrm{Hg}$. One femoral artery was cannulated for blood pressure recording and for anaerobic sampling of arterial blood. A skin incision was made over the intact skull bone to accommodate a plastic funnel for freezing of the brain in situ.

About 20-30 min after the operative procedure, when the animals were at steady state, the composition of the inspired gas was changed to include either 5 or $45 \% \mathrm{CO}_{2}$. Animals given $5 \% \mathrm{CO}_{2}$ were maintained on $25 \% \mathrm{O}_{2}$ and $70 \% \mathrm{~N}_{2} \mathrm{O}$. In experiments involving exposure to $45 \% \mathrm{CO}_{2}$ the $\mathrm{CO}_{2}$ concentration of the gas was increased gradually over a 2 min period (to counteract a fall in blood pressure). The final composition of the inspired gas was $45 \% \mathrm{CO}_{2}$ and $30 \% \mathrm{O}_{2}$ in $\mathrm{N}_{2}$. Thus, since $45 \% \mathrm{CO}_{2}$ induces anaesthesia nitrous oxide was withdrawn.

Freezing of the tissue in situ (PonTÉN et al, 1973) was started 2,5, 15, 30 and $60 \mathrm{~min}$ after the inspired $\mathrm{CO}_{2}$ tension had been increased in the $5 \%$ group and after 5 and $15 \mathrm{~min}$ in the $45 \% \mathrm{CO}_{2}$ group. Arterial blood was drawn to determine $\mathrm{P}_{\mathrm{O}_{2}}, \mathrm{P}_{\mathrm{CO}_{2}}$ and haemoglobin concentration.

The brains of animals from the unanaesthetized and anaesthetized series were dissected at $-22^{\circ} \mathrm{C}$ in a refrigerated glove box. A slice of $1-1.5 \mathrm{~mm}$ thickness was cut out from the surface of the freeze-clamped samples by means of a small buzz saw (QuistorF, 1975). Cortical tissue from this thin slice was used for analysis.

From the anaesthetized animals the superior-lateral cortical areas of one hemisphere were cut out. All samples were weighed and extracted with $\mathrm{HCl}-$ methanol. The $\mathrm{HCl}-$ methanol extracts were then brought to $0^{\circ} \mathrm{C}$ and the tissue was extracted twice with perchloric acid for subsequent enzymatic fluorometric analyses of glucose, glycogen, glucose-6-phosphate (G-6-P), fructose-6-phosphate (F-6-P), fructose-1,6-diphosphate (FDP), dihydroxyacetone phosphate (DHAP), 3-phosphoglycerate (3-PG), lactate, pyruvate, citrate, isocitrate, $\alpha$-ketoglutarate, succinate, fumarate, malate, aspartate, glutamate, glutamine, asparagine, alanine, GABA, ammonia, phosphocreatine (PCr), ATP, ADP and AMP. The methods used were those of LOWRY \& Passonneau (1972). The analytical conditions have been described in previous communications from the laboratory (Folbergroví et al., 1972a,b, 1974a,b). The oxaloacetate concentrations was calculated from the aspartate amino- transferase reaction, using an equilibrium constant of 6.7 (Krebs \& KornberG, 1957).

The results were statistically evaluated using two-sample $t$-test or Aspin-Welch's test. The following symbols are used: $* P<0.05, \dagger P<0.01, \ddagger P<0.001$.

\section{RESULTS}

\section{Unanaesthetized animals}

One control group and 3 hypercapnic groups (10, 20 and $60 \mathrm{~s}$, respectively) with 6 animals in each group were studied. The control values for arterial $\mathrm{P}_{\mathrm{CO}_{2}}$ and $\mathrm{P}_{\mathrm{O}_{2}}$ were $38.3 \pm 0.9$ and $98.8 \pm 2.4 \mathrm{~mm} \mathrm{Hg}$, respectively (means \pm S.E.M.). In the 3 hypercapnic groups $\mathbf{P}_{\mathrm{CO}_{2}}$ was $77.6 \pm 0.7,72.2 \pm 1.8$ and $69.4 \pm 2.3$ $\mathrm{mm} \mathrm{Hg}$, respectively, and arterial $P_{\mathrm{O}_{2}}$ exceeded $95 \mathrm{~mm}$ $\mathrm{Hg}$ in each animal.

As stated, the unanaesthetized animals were used to evaluate the initial changes in metabolites studied. However, since hypercapnia did not induce significant changes in organic phosphates or amino acids and since the only citric acid cycle intermediate showing a significant change was malate (a decrease from $0.309 \pm 0.006$ to $0.252 \pm 0.006 \mu \mathrm{mol} / \mathrm{g}$ at $60 \mathrm{~s}, P<$ $0.001)$ only the glycolytic metabolites will be dealt with.

Figure 1 illustrates the pattern of changes in glycolytic intermediates at 10 and $20 \mathrm{~s}$ (upper panel) and at $60 \mathrm{~s}$ (lower panel). At $60 \mathrm{~s}$, there were no significant changes in glycogen or glucose, highly significant

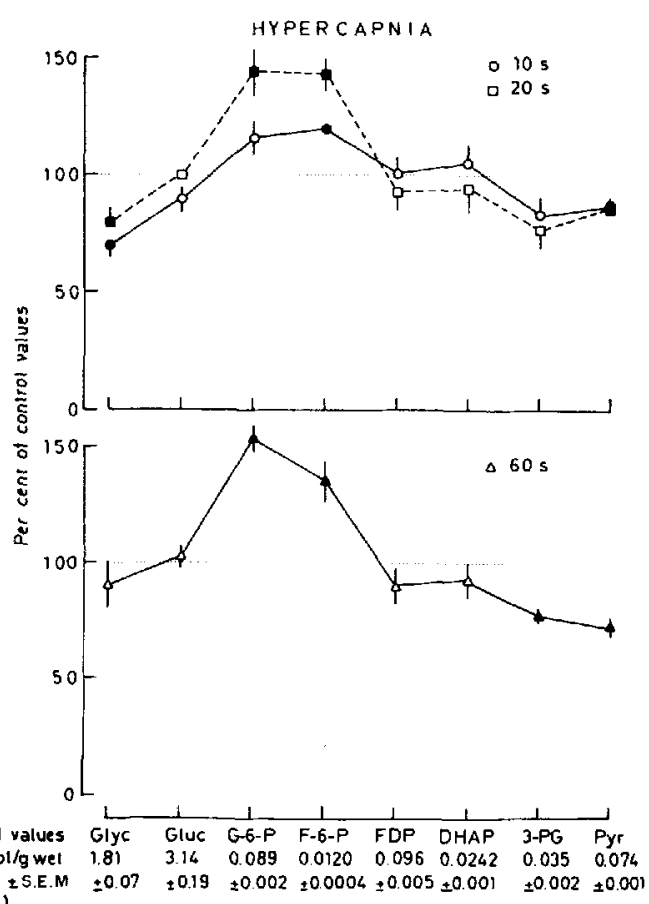
issue S.EM $=0.07=0.19=0.002=00006=0.005=0.001=0.002=0.001$ $(n=6)$

FiG. 1. Changes in the concentrations of glycolytic metabolites in the rat cerebral cortex after 10,20 and $60 \mathrm{~s}$ of hypercapnia (glycogen, glucose, glucose-6-phosphate, fructose-6-phosphate, fructose-1,6-diphosphate, dihydroxyacetone phosphate, 3-phosphoglycerate and pyruvate). The values are means \pm s.E.M. Filled symbols indicate values significantly different from the controls $(P<0.05)$. 
changes in G-6-P and F-6-P, and highly significant decreases in 3-PG and pyruvate. The data obtained at shorter exposure periods demonstrate that there was a transient decrease in glycogen concentration, that the concentrations of G-6-P and F-6-P increased during the first $20 \mathrm{~s}$, and that the pyruvate concentration was significantly reduced already at $10 \mathrm{~s}$. Two sets of results are relevant to the question of the mechanisms of the increases in G-6-P and F-6-P and of the decreases in pyruvate and lactate (not shown), respectively. First, when the hypercapnia was prolonged beyond the $10 \mathrm{~s}$ period there were further increases in G-6-P and F-6-P whereas the glycogen concentration returned at $60 \mathrm{~s}$ to normal values. Thus, it appears unlikely that G-6-P and F-6-P accumulated as a result of breakdown of glycogen (see Discussion and Folbergroví et al., 1974a). Second, the results obtained are pertinent to the mechanisms of the decrease in pyruvate concentration. Thus, the tissue lactate concentration remained unchanged at 10 and $20 \mathrm{~s}$ but decreased from a control value of $0.85 \pm 0.02$ to $0.62 \pm 0.03$ at $60 \mathrm{~s}$. Furthermore, the blood lactate and pyruvate concentrations did not decrease during the course of hypercapnia (not shown). Thus, the decrease in tissue pyruvate concentration could neither be explained in terms of a shift in the lactate dehydrogenase reaction, nor were there concentration gradients favouring transport of lactate or pyruvate from tissue to blood.

In summary, the results obtained on the unanaesthetized animals showed that during the first minute of hypercapnia there is a transient decrease in glycogen concentration, progressive increases in G-6-P and F-6-P, and decreases in pyruvate and lactate. These events precede changes occurring in citric acid cycle intermediates and amino acids, and are unaccompanied by alterations in levels of PCr, ATP, ADP and AMP.

\section{Anaesthetized animals}

In all animals the body temperature was close to $37^{\circ} \mathrm{C}$, the arterial $\mathrm{P}_{\mathrm{O}_{2}}$ exceeded $100 \mathrm{~mm} \mathrm{Hg}$, and the blood pressure was $140 \mathrm{~mm} \mathrm{Hg}$, or higher. In the $5 \%$ $\mathrm{CO}_{2}$ series the arterial $\mathrm{CO}_{2}$ tension increased from a control value of $37.2 \pm 1.1 \mathrm{~mm} \mathrm{Hg}$ to $63.9 \pm$ $1 \cdot 8,69.5 \pm 1 \cdot 2,68 \cdot 7 \pm 0.1,72 \cdot 8 \pm 0.6$ and $76.1 \pm$ 0.9 in the $2,5,15,30$ and 60 min groups, respectively. With $45 \% \mathrm{CO}_{2}$ the arterial $\mathrm{CO}_{2}$ tension was $310 \pm 9$ and $334 \pm 4$ at 5 and $15 \mathrm{~min}$, respectively.

Figure 2 illustrates the pattern of changes in citric acid cycle intermediates at 5 and $15 \mathrm{~min}$ of hypercapnia $\left(5\right.$ and $45 \% \mathrm{CO}_{2}$ ). With $5 \% \mathrm{CO}_{2}$ the results obtained after 2,30 and $60 \mathrm{~min}$ were very similar to those shown for 5 and $15 \mathrm{~min}$. The results confirm those of our previous reports in showing decreases in citrate, $\alpha-\mathrm{KG}$, malate and oxaloacetate that were proportional to the rise in $\mathrm{CO}_{2}$ tension (see FolBERGROVÁ et al., 1972b, 1974a). In addition, they show that there was a reduction in fumarate and a small rise in succinate. The increase in succinate was statis-

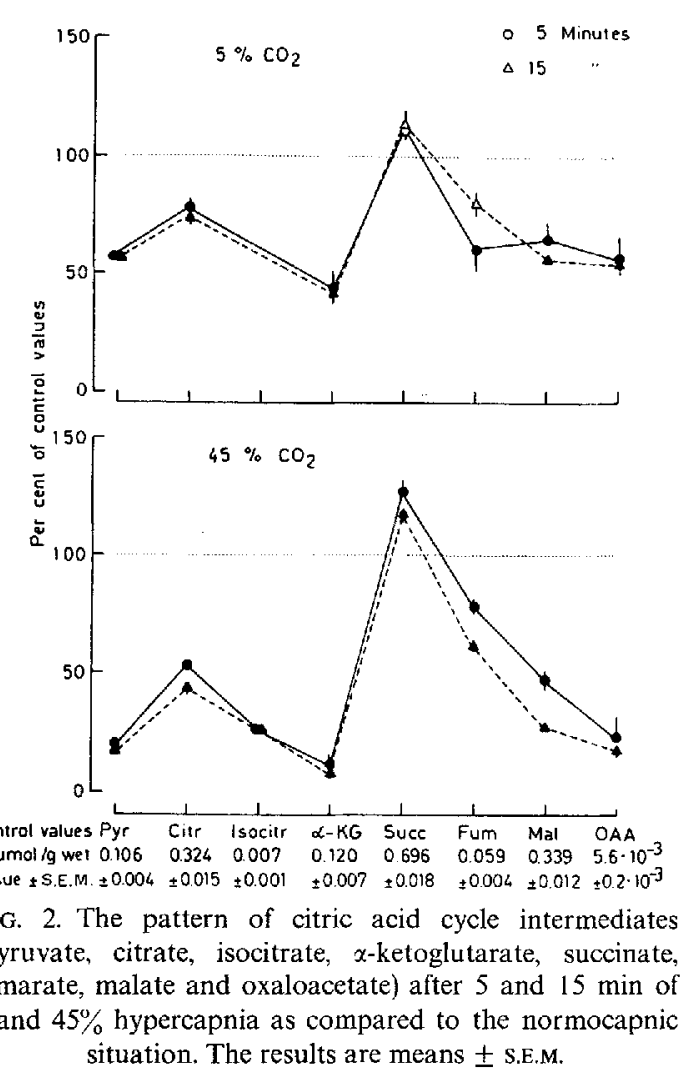

tically significant for the groups exposed to $45 \% \mathrm{CO}_{2}$ for 5 and $15 \mathrm{~min}(P<0.01)$ but not for the $5 \% \mathrm{CO}_{2}$ groups.

The rise in succinate was not sufficient to balance the reduction in concentration of other cycle intermediates. Thus, in the $45 \% \mathrm{CO}_{2}$ groups the size of the pool was reduced from $1.55 \pm 0.04 \mu \mathrm{mol} / \mathrm{g}$ to $1.29 \pm$ $0.06(P<0.01)$ and $1.10 \pm 0.02 \quad(P<0.01) \mu \mathrm{mol} / \mathrm{g}$ at 5 and $15 \mathrm{~min}$, respectively. With $5 \% \mathrm{CO}_{2}$ the pool size appeared to decrease although the changes were not statistically significant. The values were $1.58 \pm$ $0.05,1.44 \pm 0.07,1.35 \pm 0.04,1.33 \pm 0.08,1.36 \pm$ 0.05 and $1.37 \pm 0.05 \mu \mathrm{mol} / \mathrm{g}$ in the control and the $2,5,15,30$ and $60 \mathrm{~min}$ groups, respectively.

The tissue concentrations of amino acids and ammonia are illustrated in Table 1. The changes in glutamate, aspartate, glutamine and ammonia confirm our previous results (FolBERgRová et al, 1972b, $1974 a$ ). Thus, with $5 \% \mathrm{CO}_{2}$ there was a gradual fall in glutamate, a transient increase in aspartate and an increase in glutamine at $60 \mathrm{~min}$. With $45 \% \mathrm{CO}_{2}$ glutamate fell by about $4.5 \mu \mathrm{mol} / \mathrm{g}$, aspartate increased by $2.3 \mu \mathrm{mol} / \mathrm{g}$ and there was a significant rise in ammonia. GABA or asparagine did not change significantly with 5 or $45 \% \mathrm{CO}_{2}$.

There were no significant changes in alanine concentration. Data obtained with $5 \% \mathrm{CO}_{2}$ suggested that a small fall occurred in hypercapnia. However, since there was no change with $45 \% \mathrm{CO}_{2}$ we conclude that alanine concentration remains essentially unaltered in hypercapnia. 


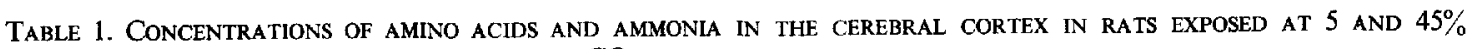
$\mathrm{CO}_{2}$ AT DIFFERENT TIMES

\begin{tabular}{|c|c|c|c|c|c|c|c|c|c|}
\hline $\begin{array}{l}\text { Experimental } \\
\text { group }\end{array}$ & $\begin{array}{l}\text { Time } \\
\text { (min) }\end{array}$ & Glut & Gln & Asp & Aspn & GABA & Ala & $\mathrm{NH}_{4}^{+}$ & $\sum_{\text {acids }}^{\text {Amino }}$ \\
\hline $5 \% \mathrm{CO}_{2}$ & $\begin{array}{r}0 \\
2 \\
5 \\
15 \\
30 \\
60\end{array}$ & $\begin{array}{c}13.67 \\
\pm 0.33 \\
12.88 \\
\pm 0.25 \\
12.86 \\
\pm 0.43 \\
12.55^{*} \\
\pm 0.26 \\
12.48 \\
\pm 0.54 \\
11.92 \dagger \\
\pm 0.28\end{array}$ & $\begin{array}{r}5.67 \\
\pm 0.09 \\
6.11 \\
\pm 0.28 \\
5.51 \\
\pm 0.37 \\
6.04 \\
\pm 0.44 \\
5.78 \\
\pm 0.30 \\
6.43^{*} \\
\pm 0.19\end{array}$ & $\begin{array}{c}3.82 \\
\pm 0.09 \\
4.62 \dagger \\
\pm 0.13 \\
4.85 \dagger \\
\pm 0.17 \\
4.62^{*} \\
\pm 0.25 \\
4.19 \\
\pm 0.15 \\
3.74 \\
\pm 0.13\end{array}$ & $\begin{array}{r}0.087 \\
\pm 0.004 \\
0.088 \\
\pm 0.002 \\
0.085 \\
\pm 0.002 \\
0.085 \\
\pm 0.003 \\
0.084 \\
\pm 0.004 \\
0.087 \\
\pm 0.004\end{array}$ & $\begin{array}{r}1.89 \\
\pm 0.04 \\
1.83 \\
\pm 0.03 \\
1.84 \\
\pm 0.07 \\
1.90 \\
\pm 0.02 \\
1.89 \\
\pm 0.07 \\
1.95 \\
\pm 0.06\end{array}$ & $\begin{array}{r}0.470 \\
\pm 0.039 \\
0.442 \\
\pm 0.023 \\
0.422 \\
\pm 0.005 \\
0.396 \\
\pm 0.025 \\
0.374 \\
\pm 0.018 \\
0.397 \\
\pm 0.035\end{array}$ & $\begin{array}{r}0.281 \\
\pm 0.043 \\
0.251 \\
\pm 0.04 \\
0.279 \\
\pm 0.038 \\
0.244 \\
\pm 0.029 \\
0.240 \\
\pm 0.041 \\
0.281 \\
\pm 0.058\end{array}$ & $\begin{array}{r}25.6 \\
\pm 0.5 \\
26.0 \\
\pm 0.3 \\
25.8 \\
\pm 0.5 \\
25.6 \\
\pm 0.8 \\
25.0 \\
\pm 0.7 \\
24.5 \\
\pm 1.1\end{array}$ \\
\hline $45 \% \mathrm{CO}_{2}$ & $\begin{array}{r}0 \\
5 \\
15\end{array}$ & $\begin{array}{c}13.19 \\
\pm 0.23 \\
10.31 \ddagger \\
\pm 0.14 \\
8.65 \ddagger \\
\pm 0.12\end{array}$ & $\begin{array}{r}5.15 \\
\pm 064 \\
4.59 \\
\pm 0.40 \\
5.53 \\
\pm 0.26\end{array}$ & $\begin{array}{r}4 \cdot 14 \\
\pm 0.16 \\
6 \cdot 19+ \\
\pm 0.19 \\
6 \cdot 41 \ddagger \\
\pm 0.27\end{array}$ & $\begin{array}{r}0.078 \\
\pm 0.003 \\
0.086 \\
\pm 0.006 \\
0.092 \\
\pm 0.005\end{array}$ & $\begin{array}{r}2.13 \\
\pm 0.08 \\
2.12 \\
+0.14 \\
2.30 \\
+0.09\end{array}$ & $\begin{array}{r}0.503 \\
\pm 0.009 \\
0.615 \\
\pm 0.044 \\
0.481 \\
\pm 0.027\end{array}$ & $\begin{array}{c}0.253 \\
\pm 0.017 \\
0.330 \\
\pm 0.037 \\
0.469 \dagger \\
\pm 0.033\end{array}$ & $\begin{array}{c}25 \cdot 2 \\
\pm 0.5 \\
23 \cdot 4 \\
\pm 0 \cdot 7 \\
22 \cdot 4^{*} \\
\pm 0.7\end{array}$ \\
\hline
\end{tabular}

The values are means \pm s.E.M. The abbreviations are as follows: Glut = glutamate, Gln = glutamine, Asp $=$ aspartate, Aspn = asparagine, GABA $=\gamma$-aminobutyric acid, Ala $=$ alanine. The concentrations are expressed in $\mu \mathrm{mol} / \mathrm{g}$ wet tissue.

The results of Table 1 indicate that there is a decrease in the amino acid pool ( $\Sigma$ amino acids) during hypercapnic conditions. With $5 \% \mathrm{CO}_{2}$ this decrease was not significant although the results obtained at 30 and $60 \mathrm{~min}$ are suggestive. With $45 \% \mathrm{CO}_{2}$ the pool size decreased significantly and at $15 \mathrm{~min}$ this decrease amounted to $2.8 \mu \mathrm{mol} / \mathrm{g}$. At this time there was also an increase in ammonia. The changes in pool size and ammonia indicate that oxidative deamination of amino acids may have occurred (see Discussion).

\section{DISCUSSION}

The new metabolites measured in the present anaesthetized series were isocitrate, succinate, fumarate, alanine, GABA and asparagine. The control values for succinate and fumarate are in good agreement with those reported by GoLDBERG et al. (1966) but the value for isocitrate was less than half of that given by these authors. In our series the extracts were not treated with Florosil for the isocitrate analyses and the fluoroscent blank was too high to allow satisfactory analyses. However, the results were internally consistent and they are reported since they clearly demonstrate a fall in isocitrate levels in hypercapnia. Our values for GABA and alanine are in good agreement with those of other workers (see DuFFy et al., 1972).

The results obtained in the present experiments have greatly facilitated the interpretation of those of the previous series (Folbergroví et al., 1972b, 1974a) and the combined results allow a tentative description of the sequence of metabolic events occurring in hypercapnia. This description must remain somewhat speculative and some aspects will require validation with other methods. However, the pattern is suffciently coherent to be presented as a framework on which subsequent experiments can be founded. Our interpretation is based on the following two facts. (1)
The initial changes affect glycolytic metabolites, and alterations in citric acid cycle intermediates and amino acids represent secondary events. (2) The citric acid cycle pool is decreased. Thus, the balance between reactions that replenish carbon skeletons to the citric acid cycle and those leading to loss of carbon atoms is shifted. Furthermore, estimation of the size of the amino acid pool, and measurement of ammonia content, indicate that amino acids are probably used as substrates during hypercapnia. When discussing the probable mechanisms involved we will make two assumptions. First, the fact that the metabolism of citric acid cycle intermediates and amino acids is compartmented in the brain (BALÁzs \& CREMER, 1973) does not influence the conclusions. Second, changes occurring during exposure to 5 and to $45 \% \mathrm{CO}_{2}$ are qualitatively similar and data obtained with $45 \% \mathrm{CO}_{2}$ can therefore be used to demonstrate changes that may escape detection with $5 \% \mathrm{CO}_{2}$. We will discuss in turn glycolytic events, and those affecting citric acid cycle intermediates and amino acids.

Glycolytic events. Of key importance is the fact that pyruvate decreases already after $10 \mathrm{~s}$ of hypercapnia. Such a decrease could occur as a result of decreased delivery or increased utilization. In all probability, the second possibility can be excluded. First, the metabolic rate for oxygen remains unchanged at $\mathrm{P}_{\mathrm{CO}_{2}}$ values of $80-90 \mathrm{~mm} \mathrm{Hg}$ (EKLÖF et al., 1973). Second, there is no indication that pyruvate or phosphoenolpyruvate is removed by accelerated $\mathrm{CO}_{2}$ fixation. Thus, instead of increasing, the citric acid cycle pool decreased. Furthermore, since the main $\mathrm{CO}_{2}$-fixing enzyme in the brain is probably pyruvate carboxylase (PATEL, 1974) the rate of $\mathrm{CO}_{2}$ fixation could vary with the pyruvate concentration, rather than with the $\mathrm{CO}_{2}$ tension or the bicarbonate concentration (see CHENG, 1971). Third, analyses of the alanine concentration give no support to the possibility that pyruvate is 
lost due to a shift in the alanine aminotransferase reaction. Fourth, the results make it less likely that lactate or pyruvate are lost from the tissue by means of transport to the blood.

Accepting that the decrease in pyruvate concentration is due to decreased delivery we must enquire into the possible mechanisms. The present results have shown that there is an accumulation of G-6-P and F-6-P during the first minute of hypercapnia. Since this accumulation does not seem to be secondary to glycogen breakdown (see also FolBerGROVÁ et al.. 1974a) it may signify inhibition of phosphofructokinase (PFK). Unequivocal proof of PFK inhibition would require that the glycolytic flux could be shown to be decreased (KREBS, 1957). Since $\mathrm{CMR}_{\mathrm{O}_{2}}$ is unchanged, at least at moderate degrees of hypercapnia (see above) a decreased glycolytic flux should mean that non-carbohydrate substrates are oxidized. Since the amino acid changes indicate that this may be the case (see below) we tentatively conclude that there is a decreased glycolytic flux due to PFK inhibition. This conclusion is entirely in keeping with previous observations on the effect of a decreased pH on PFK activity (DANFORTH, 1965).

Changes affecting citric acid cycle intermediates and amino acids. A decrease in pyruvate concentration due to diminished production implies that a condition of 'substrate depletion' is at hand. Since $\mathrm{CMR}_{\mathrm{O}_{2}}$ is unchanged, at least at moderate degrees of hypercapnia, a decreased glycolytic flux should mean that noncarbohydrate substrates are oxidized. In fact, substrate depletion during hypercapnia has some striking similarities with hypoglycaemia (LewIS et al., 1974a; NORBERG \& SiESIö, 1975). In both conditions there is a decrease in the size of the TCA pool, a shift in the aspartate aminotransferase reaction towards aspartate formation, a decrease of the amino acid pool, and an increase in ammonia. These events suggest that the non-carbohydrate substrate oxidized during hypercapnia and hypoglycaemia are at least in part tricarboxylic acid intermediates and amino acids. Normally, carbon skeletons are lost from the citric acid cycle via synthetic reactions, e.g. these leading to formation of GABA and glutamine. This loss is probably mainly replenished through $\mathrm{CO}_{2}$ fixation, and it has been estimated that about $10 \%$ of the phosphoenolpyruvate or pyruvate is diverted towards formation of malate or OAA (CHENG, 1971; BALÁzs et al., 1973). Thus, a net flux of carbon atoms is maintained from the glycolytic chain to the citric acid cycle and from the latter to the amino acid pools. However, when less pyruvate is available for oxidation there is probably a relative build-up of OAA that may have two effects. Firstly, by inducing a shift in the aspartate aminotransferase reaction it provides amino acid carbon for oxidation (see DAwSON, 1950). Secondly, by allowing a reversal of the $\mathrm{CO}_{2}$ fixation reaction it makes the citric acid cycle intermediates available for oxidation. In itself, the citric acid cycle pool is small and would not contribute significantly to the sub- strate supply. However, whether amino acids are metabolized via the glutamate dehydrogenase reaction (see Well-MaLherBe, 1971) or via the reactions of the purine nucleotide cycle (LowENSTEIN, 1972) their carbon skeletons enter the citric acid cycle before being oxidized. Thus, in hypercapnia and in hypoglycaemia the reduced availability of pyruvate seems to cause a net flux of carbon skeletons from amino acids to the citric acid cycle, and from the latter to the glycolytic chain.

Although the main metabolic events in hypercapnia can be satisfactorily explained there are some dissimilarities between hypercapnia and hypoglycaemia that warrant a discussion, and the mechanisms responsible for some of the changes observed must remain speculative. We will discuss the fate of aspartate, $\alpha-\mathrm{KG}$, alanine, glutamine and GABA.

In hypoglycaemia and in hypercapnia aspartate accumulates at the expense of glutamate, indicating that there is a shift in the aspartate aminotransferase reaction. In severe hypoglycaemia there is a massive accumulation of aspartate whereas in hypercapnia a secondary fall in aspartate to normal or subnormal values occurs (cf. Folbergroví et al., 1974a). In both conditions the accumulation of aspartate may be secondary to a relative or absolute increase in OAA. Further metabolism of aspartate would either require a reversal of the aspartate aminotransferase reaction and the subsequent deamination of glutamate, or deamination by the reactions of the purine nucleotide cycle. In hypoglycaemia, transamination could be blocked by the persisting rise in OAA caused by a depletion of NADH and a fall in malate/OAA ratio, and metabolism via the purine nucleotide cycle could be inhibited by lack of GTP (see Norberg \& Siesuö, 1975). Apparently, one or both of these pathways operate in hypercapnia.

In both hypercapnia and hypoglycaemia a rise in OAA may thus be one of the mechanisms eliciting a shift in the aspartate aminotransferase reaction. However, since $\alpha-\mathrm{KG}$ does not accumulate other reactions must accomplish $\alpha-\mathrm{KG}$ removal. In hypercapnia, carboxylation of $\alpha-K G$ to isocitrate could be one of these reactions (see CHENG, 1971). In fact, a reversal of the isocitrate dehydrogenase reaction may, in removing $\alpha-K G$, by itself induce transamination. There is thus no need to invoke reductive amination of $\alpha-\mathrm{KG}$ to explain why its concentration is maintained low. Instead, since ammonia accumulates when there is a decrease in the pool size of amino acids, the conditions seem to favour oxidative deamination of glutamate.

In hypoglycaemia, there are relatively marked decreases in alanine, GABA and glutamine. If carboxylation of $\alpha-K G$ occurs in hypercapnia lack of $\alpha-K G$ could well explain why alanine is not utilized via the alanine aminotransferase reaction, and why GABA is not metabolized. In hypoglycaemia, there appears to be a pronounced redox change in the direction of oxidation (see LewIS et al., 1974a). Lack of NADH, 
and accumulation of $\mathrm{NAD}^{+}$, could therefore enhance GABA metabolism by removing succinic semialdehyde. Thus, $\mathrm{CO}_{2}$ fixation at the $\alpha-\mathrm{KG}$ level and absence of a marked redox change could explain why alanine and GABA are not used as substrates in hypercapnia. There is no ready explanation for the delayed increase in glutamine under hypercapnic conditions. However, one factor of importance may be that accumulation of ammonia occurs without depletion of ATP and the conditions may therefore favour amidation of glutamate. In hypoglycaemia, ammonia accumulation is accompanied by energy failure (Lewis et al., 1974b) and glutamine formation could be blocked.

In summary, although the detailed mechanisms are largely unknown the present results indicate that hypercapnia leads to a relative deficiency of pyruvate and that the changes observed can be at least partly explained by the fact that citric acid cycle intermediates and amino acids are used as alternative substrates.

Acknowledgements-This study was supported by grants from the Swedish Medical Research Council (projects No 14X-263 and 14X-2179), from the Swedish Bank Tercentenary Fund, from U.S. PHS Grant No. R01 SO 7838-05 from NIH, and from the Swedish Board for Technical Development.

\section{REFERENCES}

Balázs R. \& Cremer J. E. (1973) Metabolic Compartmentation in the Brain (BALAzs R. \& Cremer J. E., eds.). Macmillan, London.

Balázs R., Machiyama Y. \& Patel A. J. (1973) in Metabolic Compartmentation in the Brain (BALAzs R. \& Cremer J. E., eds.) pp. 55-70. Macmillan, London.
CHENg S.-C. (1971) Int. Rev. Neurobiol. 14, 125-157.

DANFORTH W. H. (1965) in Control of Energy Metabolism (Chance B., Estabrook C. W. \& Williamson J. K., eds.) pp. 287-297. Academic Press, New York.

DAwson R. M. C. (1950) Biochem. J. 47, 386-395.

DufFy T. E., Nelson S. R. \& LowRY O. H. (1972) J. Neurochem. 19, 959-977.

Eklöf B., Lassen N. A., Nillson L., Norberg K. \& Siesıö B. K. (1973) Acta physiol. scand. 88, 587-589.

Folbergroví J., MacMillan V. \& Siesjö B. K. (1972a) J. Neurochem. 19, 2497-2505.

Folbergrová J., MacMillan V. \& Siesjö B. K. (1972b) J. Neurochem. 19, 2507-2517.

Folbergrové J., Pontén U. \& Siesıö B. K. (1974a) J. Neurochem. 22, 1115-1125.

Folbergrová J., LjungGren B., Norberg K. \& Siesjö B. K. (1974b) Brain Res. 80, 265-279.

Goldberg N. D., Passonneau J. V. \& Lowry O. H. (1966) J. biol. Chem. 241, 3997-4003.

KREBs H. A. \& KornberG H. L. (1957) Energy Transformations in Living Matter, pp. 213-285. Springer Verlag, Berlin.

Lewis L. D., Ljungaren B., Norberg K. \& Siesjö B. K. (1974a) J. Neurochem. 23, 659-671.

Lewis L. D., Ljunggren B., Ratcheson R. A. \& Siesjö B. K. (1974b) J. Neurochem. 23, 673-679.

Lowenstenn J. M. (1972) Physiol. Rev. 52, 382-414.

Lowry O. H. \& Passonneau J. V. (1972) A Flexible System of Enzymatic Analysis. Academic Press, New York. NORBERG K. \& Sieşö B. K. (1975) J. Neurochem. in press. NORBERG K., QUistorfF B. \& Siesıö B. K. (1975) Acta Physiol. scand. Submitted for publication.

PATEL M. S. (1974) J. Neurochem. 22, 717-724.

Pontén U., Ratcheson R. A., Satford L.-G. \& Siesjö B. K. (1973) J. Neurochem. 21, 1127-1138.

QUisTURfF B. (1975) Analyt. Biochem. In press.

Weil-Malherbe H. \& Gordon J. (1971) J. Neurochem. 18, 1659-1672. 